Review

\title{
Neolithic demic diffusion
}

\author{
Guido Barbujani
}

Department of Life Sciences and Biotechnology, University of Ferrara, Via L. Borsari 46, 44121, Ferrara, Italy; E-Mail: g.barbujani@unife.it

Received: 7 Apr 2021

Accepted: 28 Jul 2021

Published: 16 Oct 2021

Copyright: (c) 2021 by the author(s). This is an Open Access article distributed under the terms of the Creative Commons License Attribution 4.0 International (CC BY 4.0), which permits unrestricted use, distribution, and reproduction in any medium or format, provided the original work is correctly credited.

Publisher's Note: Pivot Science Publication Corp. remains neutral with regard to jurisdictional claims in published maps and institutional affiliations.

\begin{abstract}
In 1978, Paolo Menozzi, Alberto Piazza, and Luca Cavalli-Sforza paved the ground for a new multidisciplinary approach to the study of human prehistory, interpreting genetic evidence in the light of archaeological information. By producing synthetic maps of allele frequencies and summarizing them by principal component analysis (PCA), they identified an association between patterns in genetic diversity across Europe and in the Neolithic archaeological record showing the earliest documented dates of farming societies. Based on this observation, they proposed a model of demic diffusion from the Near East. They argued that the observed patterns were the result of population growth due to increased food availability in early farming communities, westward dispersal of early farmers, and relative isolation between dispersing farmers and local hunter-gatherers. These results played a major role in our understanding of the Neolithic transition, but were also criticized on methodological grounds. For instance, it has become increasingly clear that the interpretation of PCA plots is less straightforward than originally thought, and correlations should be corroborated by explicit comparison of alternative demographic models. Despite these valid criticisms, genetic and genomic studies, including those involving ancient DNA, have largely confirmed the crucial role of the Neolithic transition as a process of demographic change in European prehistory, with some qualifications. Today, there is still much to be learned about the details of that complex history, but many researchers regard the European population structure as largely reflecting the genetic consequences of three major migrations: from Africa in Upper Paleolithic times, from the Near East at the beginning of the Neolithic, and from the eastern steppes in the Bronze Age. This deep structure has not been erased, despite many additional processes involving historical migrations, isolation (i.e., drift) and local gene flow, and has been recognized thanks to the pioneering work of Menozzi, Piazza and Cavalli-Sforza.
\end{abstract}

Based on "Menozzi P, Piazza A, Cavalli-Sforza LL Synthetic maps of human gene frequencies in Europeans. Science 1978;201:786-792." 
Keywords: population structure; synthetic maps; principal component analysis; demographic history; Neolithic; gene flow

\section{Introduction}

In their 1978 Science paper, Paolo Menozzi, Alberto Piazza and Luca Cavalli-Sforza [1] showed how we could read in our cells the message sent to us by millions of ancestors, finding a way to disclose otherwise obscure aspects of our past.

Already in the 1930s, through what Julian Huxley called the modern synthesis, i.e. the development of models describing the transmission of quantitative traits (as well as the effects of inbreeding, selection, gene flow and drift), population genetics had become a fundamental tool in the study of evolution.

However, applications to humans were limited by the impossibility of conducting experiments and by the paucity of suitable data.

The word genomics did not exist at that time, but in the 1960s Luca Cavalli-Sforza was already thinking in genomic terms; he was the first to propose comparisons of multiple genes to infer the relative role of selection and drift in causing variation [2]; see Richard Nichols' contribution in this issue. Doing genomic analysis, however, was challenging at that time. Apart from the technical impossibility of directly comparing DNA sequences, it was not obvious how one could summarize variation across loci, since the data for each locus came from populations sampled at different points in the geographical space. Luca Cavalli-Sforza's intuition told him that, if he could somehow overcome these difficulties, then he could exploit the full potential of population-genetic methods and obtain new insights into human evolutionary history. Ultimately, the results went beyond everyone's expectations. The Menozzi et al. study [1] is now recognized as the starting point of a deeper investigation of the human past, based on an unprecedented dialogue among experts of diverse fields, such as paleontology, archaeology, anthropology, linguistics and, of course, population genetics.

\section{Methods}

\subsection{Interpolation}

Menozzi et al. collected data on 38 independent alleles from 10 loci, where 'independent' meant that one allele at each locus was omitted from the analysis. Some of these data came from a study of HLA markers in 67 European populations [3], while the rest were from Mourant et al.'s 
monumental compilation of blood group and serum protein variants [4]. I did not find the analyzed sample sizes for each marker in Menozzi et al. If the dataset was the same as that later used by Sokal et al. [5], as seems likely, the values ranged from 70 for phosphoglucomutase (PGM) to 870 for $A B 0$; for no population was the entire set of allele frequencies available. Making such a diverse dataset amenable to analysis was the first problem faced. The obvious strategies were clearly inefficient. If one started from the 870 localities sampled for AB0, for most of which no other genetic information was available, the enormous amount of missing data would have hampered the analysis. By contrast, most of the information would have been lost if one only considered the localities for which a certain fraction, say, $50 \%$ or even $20 \%$, of the allele frequencies were known. To counteract these problems, Menozzi et al. devised a different procedure. After mapping allele frequencies-one map for each gene-they used interpolation to calculate the allele frequencies at each of 400 preselected locations at the nodes of a grid superimposed on Europe and the Near East. With this technique, they obtained 38 allele-frequency maps, all of which included the same 400 geographical data points and hence were comparable.

\subsection{Principal component analysis (PCA)}

Menozzi et al. could then use PCA to concentrate the information contained in their 38 allele-frequency maps into a smaller number of synthetic maps, each of which accounted for a greater fraction of the overall variance than did any of the original maps. Suitable methods of multivariate analysis had already been developed in the 1930s [6]; for more details, see [7], but there had been few applications to evolutionary biology. From a geometrical standpoint, one could imagine the data as a cloud of points in a multidimensional space, each dimension representing a variable, an allele frequency in this case. The first principal component corresponds to the line passing through the multidimensional mean and minimizing the sum of the squared distances between the points and the line. Additional principal components are similarly estimated, after subtracting from the data the correlation with the previous principal component(s), for any arbitrary number of components. Principal components, termed $\mathrm{S}$ in Menozzi et al.'s (1978) paper, were calculated at each node of the grid as linear combinations of the allele frequencies:

$$
\begin{aligned}
& S_{\alpha}=\alpha_{1} p_{1}+\alpha_{2} p_{2}+\ldots \alpha_{k} p_{k} \\
& S_{\beta}=\beta_{1} p_{1}+\beta_{2} p_{2}+\ldots \beta_{k} p_{k}
\end{aligned}
$$

etc.

where $p_{1}, p_{2} \ldots p_{k}$ are the interpolated allele frequencies, and $\alpha, \beta$ etc. are the coefficients estimated so as to minimize the amount of information lost in the transformation. In this way, it was possible to subdivide the 
overall variance in components of decreasing importance, each in principle independent from the others, and each accounting for a fraction of the variance not retrieved in previous steps of the analysis.

\subsection{Mapping the principal components (PCs)}

The values of each PC were then projected onto a map of Europe. However, for purposes of graphical representation, the image generated by 400 geographical points was not sufficiently detailed. Hence, the authors recalculated the values of the PCs using a narrower grid, again by interpolation. The resulting maps were displayed on another innovative tool at that time, the computer screen. Photographs were taken, films were developed, and images were printed. Figures 1, 2 and 3, reproduced from the original article, represent the geographical distribution of the first three PCs, respectively accounting for 27,18 and $11 \%$ of the total variance.

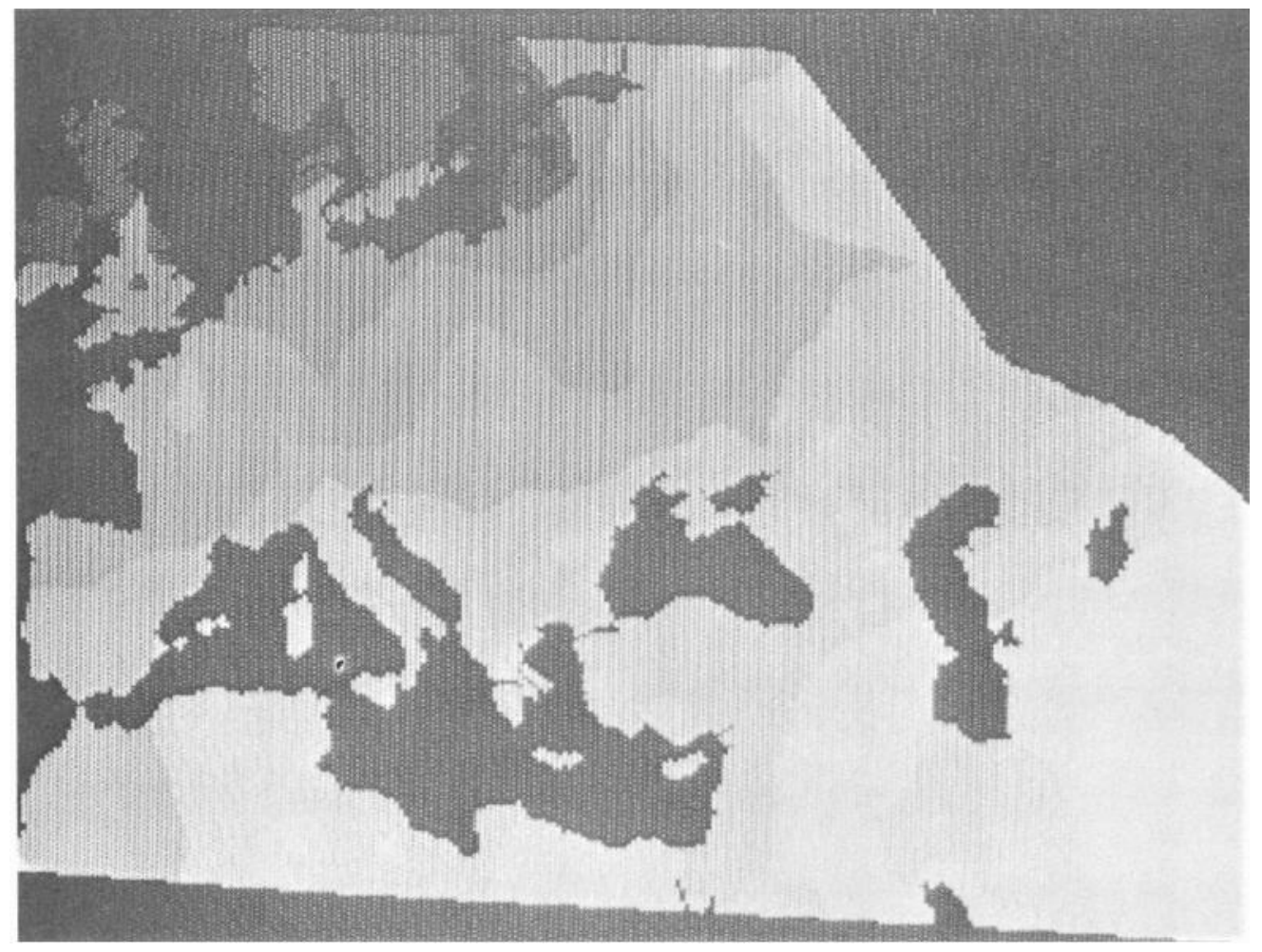

Figure 1 First PC of allele frequencies estimated from 38 allele frequencies. Reproduced by kind permission of the authors [1]. 


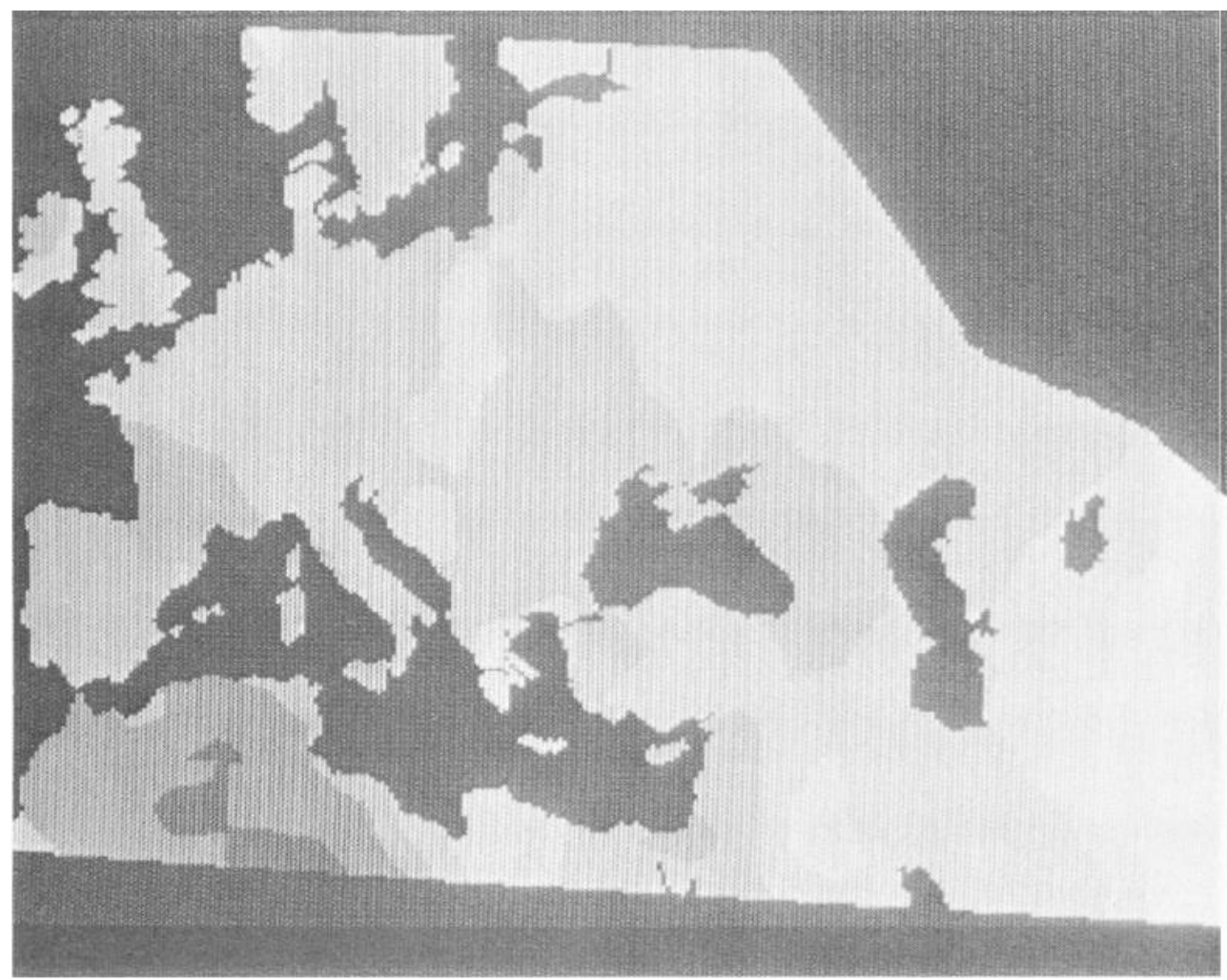

Figure 2 Second PC of allele frequencies estimated from 38 allele frequencies. Reproduced by kind permission of the authors [1].

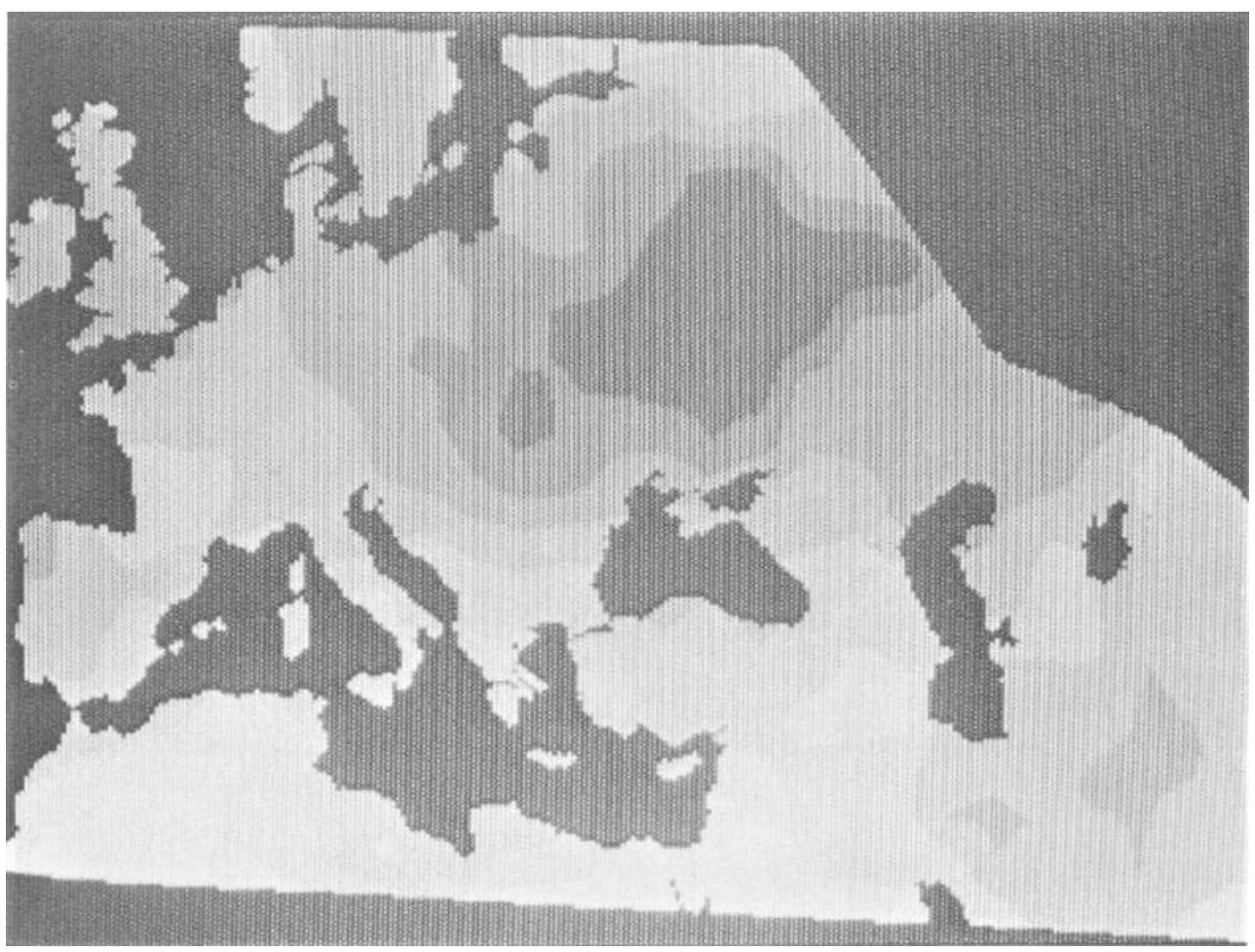

Figure 3 Third PC of allele frequencies estimated from 38 allele frequencies. Reproduced by kind permission of the authors [1]. 


\subsection{Interpreting the results: from the pattern to the process}

Archaeological evidence showed that farming activities, documented by the discovery of farming tools, large numbers of crop seeds, and later ceramics, spread in Europe from the Near East at 'a relatively slow and regular' pace, around $1 \mathrm{~km}$ per year $[8,9]$. The onset and diffusion of farming between 9000 and 5000 years BP in Europe, and later in other continents [10], was known as the Neolithic transition and is considered one of the most momentous events in human history $[11,12]$; it was then that humans began raising their food as opposed to gathering it. Schematically, one could regard it either as a mainly cultural process through adoption of new subsistence technologies by former hunting-gathering populations, or as a demographic process involving a westward and northward dispersal of Near Eastern farmers, largely replacing the indigenous residents. Of course, many intermediate possibilities exist, but it is worthwhile simplifying the debate this way for the sake of clarity. From an archaeological standpoint, there is no way to say if the same people began doing new things (a cultural development), or if new people introduced new technologies (a demographic transition). However, genetic data could help, because gene flow has recognizable genetic consequence, which are not expected under a model of cultural transmission.

Both the first PC map, and the map of the dates of earliest Neolithic sites, showed a broad, continent-wide gradient centered in the Near East, with a minimum in the British Isles and Scandinavia. Menozzi et al. concluded that the two phenomena were not only correlated, but that the genetic pattern explained the archaeological pattern; gene flow (although not exclusively, as we shall see) was the main cause of the transition observed at the archaeological level. The authors also considered the possibility that the gradient could have arisen in response to some selective pressure, but argued that climate, the most plausible selective agent, would have caused north-south, and not northwest-southeast gradients.

Finally, the consequences of another possible migration phenomenon were tentatively identified in the third PC, suggesting a westward population movement from what is now the Ukraine. The cautious interpretation put forward was that further work and a broader dataset were needed to make sure that the third PC pattern actually reflected an independent migration, and was not a statistical artifact.

Gene flow, along with genetic drift, typically generates isolation by distance patterns, whereby genetic distances between populations increase with their geographic distances. However, by itself gene flow does not necessarily generate gradients or clines, especially over such a broad range as an entire continent. A more complex model was necessary to account for the observed continent-wide pattern. Schematically, the Neolithic demic diffusion model [9] first required the 
existence of initial genetic differences between the expanding farming population and the hunting-gathering populations occupying the areas of expansion, otherwise there would be no apparent effect of gene flow at the genetic level. Second, because of the new subsistence technology, more resources became available to the farming population so that it grew in size. Third, once the carrying capacity of the territory had been reached, the population would disperse in search of new arable land; this dispersal process was envisaged as a gradual phenomenon, rather than as a long-range, mass migration. Fourth, in the newly expanded territories, farmers and hunter-gatherers coexisted for some time without admixing. The farming component of the population kept growing, while the hunting-gathering component did not, so when the carrying capacity of the new territory had been reached, prompting a further dispersal, the dispersing group would contain a majority of people descended from Near Eastern farmers, and a minority of descendants of local hunter-gatherers. Under this stepping-stone model of population structure, the process would generate broad clines encompassing a vast territory (Figure 4).

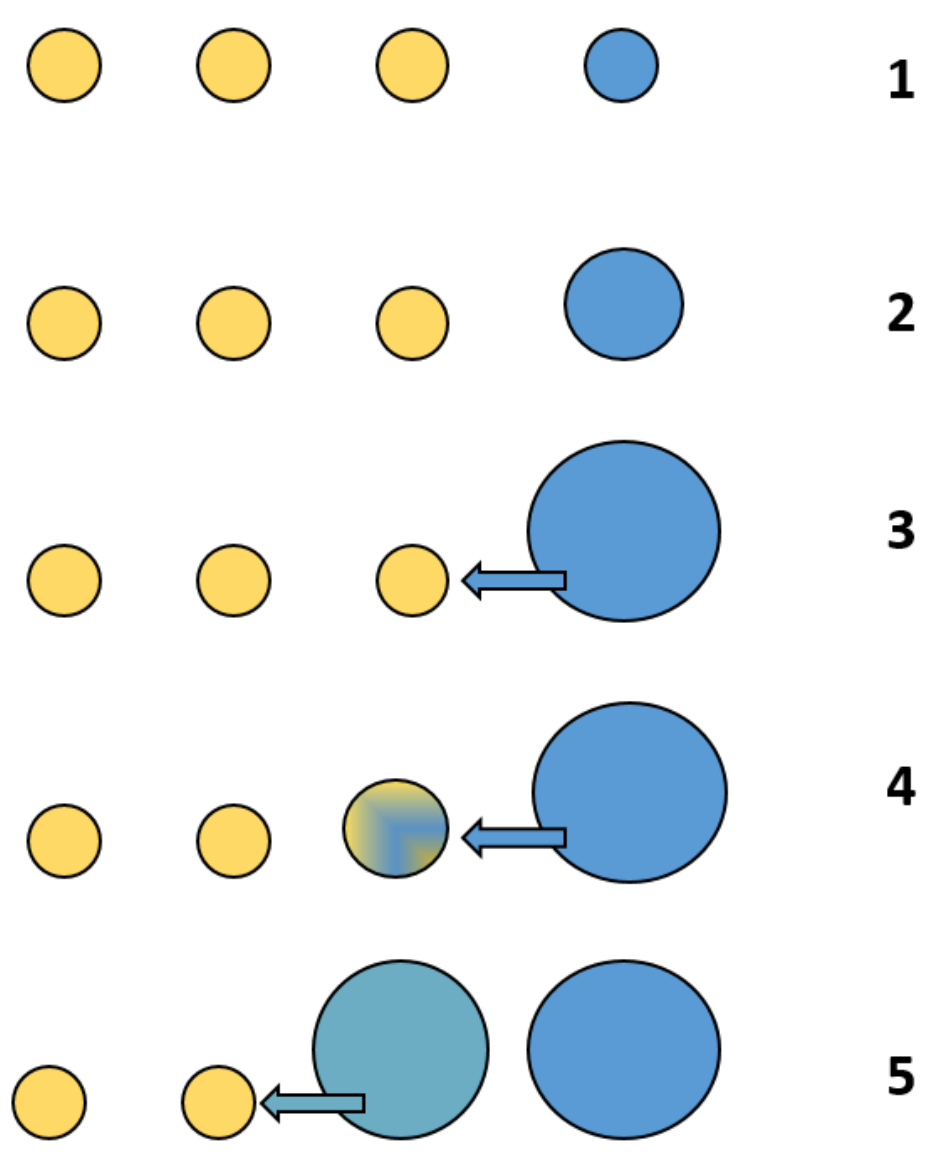

Figure 4 Schematic representation of the processes leading to demic diffusion. The size of the circles represents population sizes, and the color their origin: early near Eastern farmers (blue) or European huntergatherers (yellow). Arrows indicate migration. See text for a description of the five phases outlined in the figure. 


\subsection{Alternative models and methodological issues}

An immediate consequence of this paper was the creation of a successful neologism, paleogenetics [13]. As of July 2021, Scopus reported 437 citations of the paper, generally positive with some enthusiastic comments; but some questions had arisen. Are we sure that the observed clines do not reflect selection, rather than population growth and dispersal? Clines do not carry a date, so could other prehistoric or historic migrations lead to the same results? Other comments had to do with methodological issues, such as the effects of interpolation and the possibility that PCA identifies patterns even where they do not exist.

The possible effects of selection were addressed mainly by simulation and analogy with patterns observed at single loci [14]. In general, although it is notoriously difficult to prove or disprove selection by analyzing allele-frequency variation, the opinion prevailed that selection should affect specific loci, and not multiple loci on different chromosomes $[2,15]$. Rather, some simulation studies showed that European allelic diversity was also consistent with distributions generated by replacement of hunter-gatherers by expanding farmer populations, where clines resulted from repeated founder effects during the expansion $[16,17]$. This observation led to questioning whether processes other than demic diffusion, or occurrences in periods other than the Neolithic, could provide an explanation for the observed clinal patterns.

The strongest challenge to the model of Neolithic demic diffusion came from an emerging research field, phylogeography. As mitochondrial DNA data became available and then abundant, building haplotype networks became a popular approach, as well as the more or less arbitrary clustering of haplotypes into 'haplogroups'. Under two very strong simplifying assumptions, the networks returned information that was regarded as inconsistent with major effects of Neolithic processes. Following Richards et al. [18], the assumptions were: (1) each cluster in its entirety could be assigned to one of the main migration phases, Neolithic or Paleolithic; (2) the age of each cluster (i.e., its coalescence time) closely approximated the timing of the migration event. In other words, under assumption 2 the occurrence of a mutation is followed by a migration that will spread the new allele over the geographical space. In this way, phylogeographic analyses systematically estimated all migration phenomena at earlier times. In particular, every European haplogroup but one (J) had a coalescence time greater than 9000 years. This led to the proposal that the spread of agriculture was mostly an indigenous development (for an interpretation of the archaeological record under this view, see e.g., [19]) and that the European population structure was established in Paleolithic times (see e.g., [20,21], and, for the Y chromosome, [22]). In 
particular, haplogroup $\mathrm{H}$ was regarded and heralded as the molecular signature of Paleolithic Europeans [23]. In the phylogeographic literature, no attempt was made to reconcile these results with the clines observed in protein variation, but a cline of mitochondrial diversity matching the cline described in Menozzi et al.'s first PC was actually identified, which was more significant in the southern part of the continent than in the northern part [24].

The conclusions of the phylogeographic studies rested crucially on the assumption that the date of a migration can be regarded as the coalescence time of a cluster of mitochondrial DNAs. This view overlooked a key basic concept, that a mitochondrial mutation is a biochemical change affecting an egg cell in a woman, whereas a migration is a demographic process affecting many people. Rigorous application of these principles leads to nonsense. Mitochondrial haplogroup $U$, and hence the entire mitochondrial genealogy, predates the arrival in Europe of the first anatomically modern humans [18], which can only mean that the relevant mutation occurred when the Europeans' ancestors lived somewhere else. It is now clear that the average coalescence time of two sequences sampled from two diverging populations is much older than the split of the groups [25]. Unless a group colonizing a new territory passes through a radical bottleneck, it will keep part of its initial genetic diversity. Therefore, the coalescence times inferred from samples of its descendants will be close to the coalescence times of the population of origin, consistently overestimating the age of the derived populations [26]. In short, people, not haplogroups, migrate [27]; hence, inferences about population history require clear models that consider demography and the effects of sampling, not just measures of genetic diversity between molecules [28-30]. Analyses of ancient DNA have now disproved the interpretations put forward in phylogeographic studies, incidentally showing that it was the Neolithic demic diffusion that introduced haplogroup $\mathrm{H}$ in Europe [31].

Other criticisms concerned the application of PCA to spatial data, which by their nature show some degree of autocorrelation. Simulation studies showed that mathematical artifacts might indeed arise, raising the possibility that clines in PCs may not necessarily reflect specific migration events. For instance, a tendency of the second $P C$ to be orthogonal in space to the first PC was noted [32]. In addition, PCA results seem to be affected by the distribution of sampling locations. Interpolation generates local gradients of allele frequency, and it is unclear to what extent the broad gradients observed at the continental level reflect artificial, local ones [32-34]. In contrast, McVean showed that PCA applications in population genetics had a solid foundation, because evolutionary phenomena leading to various patterns of genetic diversity in space, such as the presence or absence of gene flow, result in different shapes of the genealogical 
tree and in different PCA results [35]. The main problem seems to be that in PCA analysis (and not only there), different processes may eventually produce the same pattern, making interpretation of the results equivocal. In this, as in many other instances, conclusions based on descriptive statistics need to be supported by explicit comparisons with alternative hypotheses [16,30,36-38].

We can safely say that, like any other statistical tool, PCA requires assumptions, which may be more or less justified in the context of the particular scientific questions being addressed. We are now more aware of several limitations of the approach; despite all that, it is remarkable that PCA has become an indispensable (we might say, inevitable) tool for exploratory analysis of population-genomic data $[39,40]$. This is even more remarkable in light of the fact that the sheer amount of genomic information now available makes PCA less effective than it was for describing allele frequencies. PC1 and PC2 of Menozzi et al. accounted for $45 \%$ of the overall variance, whereas in modern genomic studies values around $3 \%$ are considered satisfactory. As we know, it is not a good idea to draw strong conclusions from a single study based on a single method. However, Menozzi et al.'s main conclusion, now more accurately qualified in the light of later findings in archaeology and genetics, is still essential to an understanding of the prehistorical phenomena that led to the establishment of the European population structure. Its strongest confirmation comes from the abundant body of ancient DNA data.

\section{The Neolithic Demic Diffusion Today}

The main difference between what we know (or think we know) today and what was known when the model of Neolithic demic diffusion was put forward depends not only on the enormous amount of genomic information now available, but also on our knowledge of past genetic diversity. Ancient DNA has revolutionized the field, allowing us to study directly what once could only be investigated indirectly.

Let us not forget that the typical difference between two randomly selected human genomes is around 20 million base pairs [41], i.e., $0.3 \%$ of the total 6.5 billion base pairs. All the following considerations will then refer to that small, variable fraction of the genome. Schematically, it seems that the oldest Eurasians studied at the genomic level, 45,000 to 37,000 years ago, did not contribute to the genetic diversity of present day people in Europe [42]. The first specimens clearly showing a shared ancestry with modern Europeans belong to the period between 37,000 and 14,000 years $\mathrm{BP}$, and appear to be descended from a single founder population, which separated from East Asians 45,000 to 55,000 years BP [42,43]. Around 14,000 years ago, a major population turnover occurred, where most of the previous Paleolithic people in Europe were replaced by a population of hunter-gatherers sharing common genomic features, now referred to as 
western hunter-gatherers, or WHGs $[42,44,45]$. With the Neolithic transition, ancient DNA studies record the spread all over Europe of a new genomic component related to modern populations from the Near East $[44,46]$. The ability to recover nuclear DNA even from highly damaged samples, allowed ancient DNA studies to identify the main source of this early Neolithic component in early farmers from northwest Anatolia or the east Anatolian fault (EAF) $[47,48]$ and, ultimately in ancient populations from the southern Levant and Iran $[48,49]$.

A later migration movement starting some 5000 years ago in the Bronze Age, from the Pontic-Caspian steppes, led to the diffusion of the steppe, or Yamnaya (YAM) genomic features in central and northern Europe $[50,51]$. These were apparently a mix of Eastern and Caucasian hunter-gatherers that included a genomic component from Iranian farmers. Most European genomes, both ancient and contemporary, can be modeled as a combination of WHG, EAF and YAM components [51], although in specific zones the composition of the population and its history are somewhat different [52,53]. For instance, the YAM component is virtually absent in many areas of southern Europe [54]. The EAF and YAM components show two opposite clines, with the former reaching its maximum in southern Europe ( $90 \%$ in Sardinia) and its minimum in the Baltic area (10\% in Estonia). Symmetrically, the genome component attributed to YAM has a maximum in Norway $(>50 \%)$ and a minimum in Sardinia $(<5 \%)$. The WHG component is scantily present all over the continent, never reaching values $>15 \%$, except in Estonia and Lithuania [51]. These results support a view of European genomic evolution in which the first hunter-gatherers left significant, but small, traces in various populations. At later times, two major migrations brought in the main genomic components. First, there was the demic diffusion of early Near Eastern farmers at the beginnings of the Neolithic; later, in the Bronze Age, pastoralist Yamnaya people came from the Ukrainian steppes, people whose ancestors were likely affected by a northward Neolithic diffusion from Anatolia or Iran [55]. The effects of Neolithic and Bronze Age migrations appeared in several diachronic studies of European populations [39], and match beautifully with the patterns described by Menozzi et al. in their PC1 and PC3. Modern genomic analyses show how deep was Menozzi et al.'s insight into the demographic history of Europe, despite the minimal amount of data they could analyze.

Recent studies showed that demographic growth in what would later become the farming populations started long before the Neolithic, suggesting that farming might have been a consequence of increasing numbers of people to feed, rather than its cause [56]. The geographical details of the early Neolithic farmers' expansion in Europe are now beginning to be recognized in finer detail, both along a maritime route and through the traditional terrestrial lines of expansion [57]. In short, although it is often useful to schematically oppose alternative 
hypotheses, demic diffusion was the main, but not the only, process leading to the spread of agriculture in Europe. Different phenomena, both demographic and cultural, were probably important in different regions and at different times [58], and can now be dissected and carefully described by multidisciplinary studies of genetic, fossil and archaeological evidence. An archaeological study of the Neolithic transition phase across Europe seems to support the idea that the spread of Neolithic cultures was essentially a migratory process in the south, but not so much so in the north of Europe, where continuity of pre-Neolithic body ornaments across the Neolithic transition was observed [59].

Historical linguistics is also a potentially important component of the multidisciplinary effort to understand our prehistory (see Giuseppe Longobardi's contribution). Another effect of Menozzi et al.'s study was to start a debate on the relationship between genetics and linguistics. Traditional linguists and archaeologists tend to identify the first IndoEuropean speakers with steppe pastoralists from the current Ukraine, who dispersed during the Bronze Age $[60,61]$. By contrast, after a careful comparison of archaeological, linguistic, and genetic evidence, Colin Renfrew $[11,62]$ proposed that it was the early farmers from the Near East who introduced their language, an early form of Indo-European, into Europe, along with their new subsistence technologies and their genes. I shall not get into the details of this controversy here, although the absence of the YAM component in Bronze-Age, Indo-Europeanspeaking, populations of Greece [54] seems hard to reconcile with the view that the first Indo-European speakers entered Europe from the north in the Bronze Age (as in Ref. 51). Rather, I would like to stress that Colin Renfrew's proposal, besides being well supported by analyses of Indo-European vocabularies by the methods of evolutionary biology [63], offers an answer to another, final question I have not mentioned. Why did the first Near Eastern farmers move northwest, and not in other directions? If Colin Renfrew's [62] views are correct, the simple answer would be that east and south of where they lived there were other early farming communities, who, more or less at the same time, were similarly growing in numbers and expanding where they could, eastwards and southwards, leading to the spread of other language families. To the best of my knowledge, this hypothesis has never been tested using genomic data. However, it successfully predicted Eurasian patterns of genetic diversity when all we had to study was a handful of protein polymorphisms [64].

\section{Competing Interests}

Guido Barbujani is the Editor-in-Chief of the journal Human Population Genetics and Genomics. He was not involved in the review or decisions related to this manuscript. 


\section{Acknowledgements}

I thank Paolo Menozzi and Alberto Piazza for the permission to reuse photographic material from their 1978 paper, and Lounès Chikhi and Gloria González-Fortes for many suggestions and critical reading of the manuscript.

\section{References}

1. Menozzi P, Piazza A, Cavalli-Sforza LL. Synthetic maps of human gene frequencies in Europeans. Science. 1978; 201:786-792. DOI

2. Cavalli-Sforza LL. Population structure and human evolution. Proc R Soc Lond B Biol Sci. 1966:164(995):362-379.

3. Ryder LP, Anderson E, Svejgaard A. An HLA map of Europe. Hum Hered. 1978;28:171-200. DOI

4. Mourant AE, Kopec AC, Domanyiewska-Sobczak K. The distribution of the human blood groups. Oxford: Blackwell; 1976.

5. Sokal RR, Oden NL, Legendre P, Fortin M-J, Kim J, Thomson BA, et al. Genetics and language in European populations. Am Nat. 1990;135:157-175. DOI

6. Hotelling $\mathrm{H}$. Analysis of a complex of statistical variables into principal components. J Educat Psychol. 1933;24(6):417-441,498520. DOI

7. Jolliffe IT. Principal component analysis. 2nd edition. New York: Springer Series in Statistics; 2002.

8. Ammerman J, Cavalli-Sforza LL. Measuring the rate of spread of early farming in Europe. Man. 1971;6:674-688. DOI

9. Ammerman J, Cavalli-Sforza LL. A population model for the diffusion of early farming in Europe. In The explanation of cultural change: Models in prehistory (C. Renfrew, ed.). London: Duckworth, 1973; pp. 335-358.

10. Bellwood P. First farmers. The origins of agricultural societies. Malden (USA): Blackwell; 2005.

11. Renfrew $C$. Before Babel: Speculations on the origins of linguistic diversity. Cambridge Archaeol J. 1992;1:3-23. DOI

12. Foley RA, Martin L, Mirazón Lahr M, Stringer C. Major transitions in human evolution. Phil Trans R Soc B. 2016;371:20150229. DOI

13. Schwidetzky, I. Paleo-population genetics. J Hum Evol. 1979;8:661-667.

14. Fix AG. Gene frequency clines in Europe: demic diffusion or natural selection? J Royal Anthropol Inst. 1996;2:625-643. DOI

15. Fan S, Hansen MEB, Lo Y, Tishkoff SA. Going global by adapting local: A review of recent human adaptation. Science. 2016;354:54-59. DOI

16. Barbujani G, Sokal RR, Oden NL. Indo-European origins: a computer-simulation test of five hypotheses. Am J Phys Anthropol. 1995;96:109-132. DOI

17. Fix AG. Gene frequency clines produced by kin-structured founder effects. Hum Biol. 1997;69(5):663-673. 
18. Richards M, Macaulay V, Hickey E, Vega E, Sykes B, Guida V, et al. Tracing European founder lineages in the Near East mtDNA pool. Am J Hum Genet. 2000;67:1251-1276.

19. Zvelebil M. On the transition to farming in Europe, or what was spreading with the Neolithic: a reply to Ammerman. Antiquity. 1989;63:379-383. DOI

20. Torroni A, Richards M, Macaulay V, Forster P, Villems R, Norby S, et al. mtDNA haplogroups and frequency patterns in Europe. Am J Hum Genet. 2000;66:1173-1177. DOI

21. Soares P, Achilli A, Semino O, Davies W, Macaulay V, Bandelt HJ, et al. The archaeogenetics of Europe. Curr Biol. 2010;20:R174-R183. DOI

22. Semino O, Passarino G, Oefner PJ, Lin AA, Arbuzova S, Beckman LE, et al. The genetic legacy of Paleolithic Homo sapiens sapiens in extant Europeans: a $\mathrm{Y}$ chromosome perspective. Science. 2000;290:1155-1159. DOI

23. Achilli A, Rengo C, Magri C, Battaglia V, Olivieri A, Scozzari R, et al. The molecular dissection of mtDNA haplogroup $\mathrm{H}$ confirms that the Franco-Cantabrian glacial refuge was a major source for the European gene pool. Am J Hum Genet. 2004;75:910-918. DOI

24. Simoni L, Calafell F, Pettener D, Bertranpetit J, Barbujani G. Geographic patterns of mtDNA diversity in Europe. Am J Hum Genet. 2000;66:262-278. DOI

25. Nichols RA. Gene trees and species trees are not the same. Trends Ecol Evol. 2001; 16(7):358-364. DOI

26. Barbujani G, Bertorelle G, Chikhi L. Evidence for Paleolithic and Neolithic gene flow in Europe. Am J Hum Genet. 1998;62:488-491. DOI

27. Goldstein DH, Chikhi L. Human migrations and population structure: What we know and why it matters. Annu Rev Genomics Hum Genet. 2002;3:129-152. DOI

28. Chikhi L, Nichols RA, Barbujani G, Beaumont MA. Y. genetic data support the Neolithic demic diffusion model. Proc Natl Acad Sci USA. 2002;99:11008-11013. DOI

29. Barbujani G, Goldstein DB. Africans and Asians abroad: genetic diversity in Europe. Annu Rev Genom Human Genet. 2004;5:119150. DOI

30. Itan $Y$, Powell A, Beaumont MA, Burger J, Thomas MG. The origins of lactase persistence in Europe. PLoS Comput Biol. 2009;5:e1000491. DOI

31. Fu Q, Rudan P, Pääbo S, Krause J. Complete mitochondrial genomes reveal Neolithic expansion into Europe. PLoS One. 2012;7:e32473. DOI

32. Novembre J, Stephens M. Interpreting principal component analyses of spatial population genetic variation. Nature Genet. 2008;40:646-649. DOI 
33. Sokal RR, Oden NL, Thomson BA. A problem with synthetic maps. Hum Biol. 1999;71:607-619.

34. Rendine S, Piazza A, Cavalli-Sforza LL. A problem with synthetic maps: Reply to Sokal et al. Hum Biol. 1999;71:15-25.

35. McVean G. A genealogical interpretation of principal components analysis. PLoS Genet. 2009;5:e1000686. DOI

36. Dupanloup I, Bertorelle G, Chikhi L, Barbujani G. Estimating the impact of prehistoric admixture on the Europeans' genome. Mol Biol Evol. 2004;21:1361-1372. DOI

37. Currat $M$, Excoffier $L$. The effect of the Neolithic expansion on European molecular diversity. Proc R Soc B. 2005;272:679-688. DOI

38. Rasteiro R, Bouttier PA, Sousa VC, Chikhi L. Investigating sex-biased migration during the Neolithic transition in Europe, using an explicit spatial simulation framework. Proc Biol Sci. 2012; 279:24092416. DOI

39. Antonio ML, Gao Z, Moots HM, Lucci M, Candilio F, Sawyer S, et al. Ancient Rome: A genetic crossroads of Europe and the Mediterranean. Science. 2019;366(6466):708-714. DOI

40. Yang MA, Fan X, Sun B, Chen C, Lang J, Ko YC, et al. Ancient DNA indicates human population shifts and admixture in northern and southern China. Science. 2020;369:282-288. DOI

41. 1000 Genomes Project Consortium. A global reference for human genetic variation. Nature. 2015;526:68-74. DOI

42. Fu Q, Posth C, Hajdinjak M, Petr M, Mallick S, Fernandes D, et al. The genetic history of Ice Age Europe. Nature. 2016;534:200-205. DOI

43. Skoglund $P$, Mathieson I. Ancient human genomics: The first decade. Annu Rev Genom Hum Genet. 2018;19:381-404. DOI

44. Lazaridis I, Nadel D, Rollefson G, Merrett DC, Rohland N, Mallick S, et al. Genomic insights into the origins of farming in the ancient Near East. Nature. 2016;536(7617):419-424. DOI

45. Posth C, Renaud G, Mittnick A, Drucker DG, Rougier H, Cupillard C, et al. Pleistocene mitochondrial genomes suggest a single major dispersal of non-Africans and a late glacial population turnover in Europe. Curr Biol. 2016;26:827-833. DOI

46. Olalde I, Schroeder H, Sandoval-Velasco M, Vinner L, Lobón I, Ramirez $\mathrm{O}$, et al. A common genetic origin for early farmers from Mediterranean cardial and Central European LBK cultures. Mol Biol Evol. 2015;32: 3132-3142. DOI

47. Omrak A, Günther T, Valdiosera $C$, Svensson EM, Malmström H, Kiesewetter $\mathrm{H}$, et al. Genomic evidence establishes Anatolia as the source of the European Neolithic gene pool. Curr Biol. 2015;26:270275. DOI

48. Lazaridis I, Patterson N, Mittnik A, Renaud G, Mallick S, Kirsanow K, et al. Ancient human genomes suggest three ancestral populations for present-day Europeans. 2014;513(7518):409-13. DOI 
49. Broushaki F, Thomas MG, Link V, López S, van Dorp L, Kirsanow K, et al. Early Neolithic genomes from the eastern Fertile Crescent. Science. 2016;353(6298):499-503. DOI

50. Allentoft ME, Sikora M, Sjögren KG, Rasmussen S, Rasmussen M, Stenderup J, et al. Population genomics of Bronze-Age Europe. Nature. 2015;522(7555):167-72. DOI

51. Haak W, Lazaridis I, Patterson N, Rohland N, Mallick S, Reich D. Massive migration from the steppe was a source for Indo-European languages in Europe. Nature. 2015;522(7555):207-11. DOI

52. Jones ER, Zarina G, Moiseyev V, Lightfoot E, Nigst PR, Manica A, et al. The Neolithic transition in the Baltic was not driven by admixture with early European farmers. Curr Biol. 2017;27:576-582. DOI

53. Günther T, Malmström H, Svensson EM, Omrak A, Sánchez-Quinto F, Kılınc GM, et al. Population genomics of Mesolithic Scandinavia: investigating early postglacial migration routes and high latitude adaptation. PLOS Biol. 2018;16:e2003703. DOI

54. Clemente $F$, Unterländer M, Dolgova O, Amorim CEG, CoroadoSantos F, Neuenschwander S, et al. The genomic history of the Aegean palatial civilizations. Cell. 2021;184:2565-2586.e21. DOI

55. Santos P, González Fortes GM, Trucchi E, Ceolin A, Cordoni G, Guardiano $C$, et al. More rule than exception: Parallel evidence of ancient migrations in grammars and genomes of Finno-Ugric speakers. Genes. 2020;11:1491. DOI

56. Leonardi M., Barbujani G., Manica A. An earlier revolution: genetic and genomic analyses reveal pre-existing cultural differences leading to Neolithization. Sci Rep. 2017;7:3525. DOI

57. Fernández E, Pérez-Pérez A, Gamba C, Prats E, Cuesta P, Anfruns J, et al. Ancient DNA analysis of 8000 B.C. near eastern farmers supports an early neolithic pioneer maritime colonization of Mainland Europe through Cyprus and the Aegean Islands. PLoS Genet. 2014;10:e1004401. DOI

58. González-Fortes G, Jones ER, Lightfoot E, Bonsall C, Lazar C, Grandald'Anglade $A$, et al. Paleogenomic evidence for multi-generational mixing between neolithic farmers and mesolithic hunter-gatherers in the lower Danube Basin. Curr Biol. 2017;27:1801-1810. DOI

59. Rigaud S, d'Errico F, Vanhaeren M. Ornaments reveal resistance of North European cultures to the spread of farming. PloS ONE. 2015;10:e0121166. DOI

60. Gimbutas M. The Indo-Europeanization of Europe: the intrusion of steppe pastoralists from south Russia and the transformation of Old Europe. Word. 1993;44:205-222. DOI

61. Anthony D. The horse, the wheel, and language: how Bronze-Age riders from the Eurasian steppes shaped the modern world. Princeton: Princeton University Press; 2010. DOI

62. Renfrew C. Archaeology and language. The puzzle of Indoeuropean origins. London: Jonathan Cape; 1987. 
63. Bouckaert R, Lemey P, Dunn M, Greenhill SJ, Alekseyenko AV, Drummond $A J$, et al. Mapping the origins and expansion of the Indo-European language family. Science. 2012;337:957-960. DOI

64. Barbujani G, Pilastro A. Genetic evidence on origin and dispersal of human populations speaking languages of the Nostratic macrofamily. Proc Natl Acad Sci USA. 1993;90:4670-4673. DOI

Cite this article: Barbujani G. Neolithic demic diffusion. Hum Popul Genet Genom 2021;1(1): 0005. https://doi.org/10.47248/hpgg2101010005 